\title{
A Model for Ultrasonic Backscatter from Trabecular Bone
}

\author{
Keith A. Wear \\ U.S. Food and Drug Administration, \\ Center for Devices and Radiological Health, \\ Rockville, MD 20852
}

Abstract - A model describing the frequency dependence of backscatter from trabecular bone is presented. Scattering is assumed to originate from the surfaces of trabeculae, which are modeled as long thin cylinders. Measurements from human calcaneus in vitro are in good agreement with theory. For mediolateral insonification at diagnostic frequencies, backscatter coefficient is approximately proportional to frequency cubed. At higher frequencies, the frequency response flattens out.

\section{INTRODUCTION}

Compared with X-ray bone densitometry, ultrasound is inexpensive, fast, and portable. Calcaneal ultrasonic attenuation and sound speed correlate highly with calcaneal bone mineral density (BMD) [1-6] which is an indicator of osteoporotic fracture risk [7]. Calcaneal ultrasonic measurements have been clinically demonstrated to be predictive of fractures of the hip and other sites [8-13].

The calcaneus consists of trabecular bone surrounded by a thin cortical shell. The trabecular interior consists of a three dimensional lattice of branching spicules or plates. The spaces between the trabeculae are filled with marrow. The interfaces between mineralized bone trabeculae and marrow are likely candidates for the sources of ultrasonic scattering.

Ultrasonic backscattering properties may provide useful structural information. For example, the aging process involves a reduction over time of the number and thicknesses of trabeculae. This would be expected to reduce backscatter. Some diagnostic promise for this measurement has already been demonstrated [14-17]. Although the utility of bone sonometry has been established, the fundamental mechanisms underlying the interaction between ultrasound and bone are currently not well understood. The objective of this paper is to investigate ultrasonic scattering in trabecular bone. Toward this end, a theoretical model with experimental corroboration is presented.

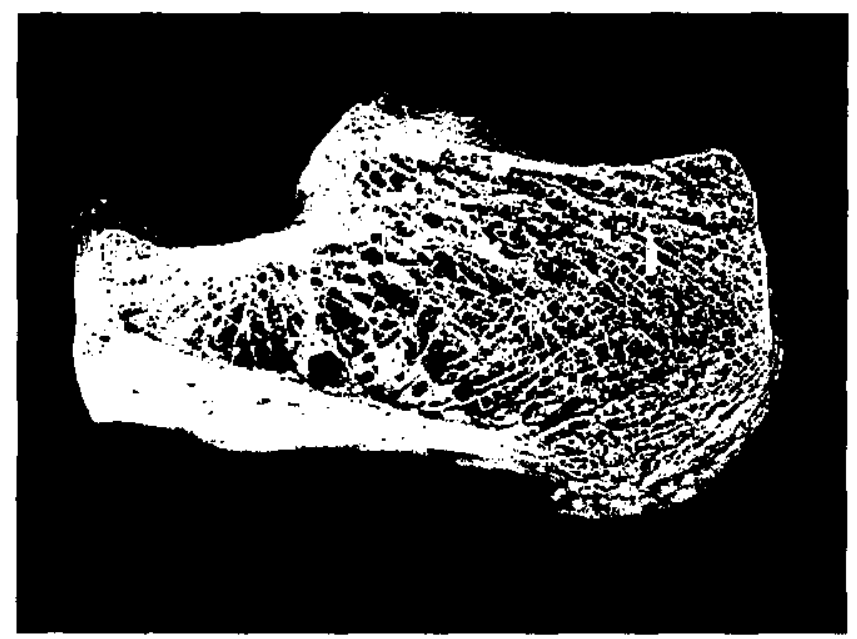

Figure 1. Calcaneus sample with lateral cortical layers removed. Long thin trabeculae are apparent.

\section{MODEL}

Trabeculae within bone are postulated to be the main sources of scattering and are modeled here as cylinders with diameters that are small relative to the wavelength. It is assumed that the cylinders are long relative to the ultrasonic beam cross section and are oriented perpendicular to the ultrasound propagation direction. Figure 1 shows long thin trabeculae within a calcaneus. Although they exhibit a myriad of orientations, the trabeculae are all approximately perpendicular to the ultrasound propagation direction provided that the bone is interrogated in the mediolateral (or lateromedial) direction (perpendicular to the plane of Figure 1). A typical value for human calcaneal trabecular thickness is $120 \pm 10 \mu \mathrm{m}$ (mean \pm standard 
deviation) [18]. The wavelengths (in water) used in the experiment were much larger and ranged from $3.1 \mathrm{~mm}$ (at $500 \mathrm{kHz}$ ) to $0.7 \mathrm{~mm}$ (at $2.25 \mathrm{MHz}$ ).

The intensity of an acoustic wave scattered from a solid cylinder, is given by $I_{s}=I \alpha\left|\varphi_{s}(\phi)\right|^{2} / \pi r$ where $I$ is the intensity of the incident plane wave, $\alpha$ is the radius of the cylinder, $r$ is the distance from the cylinder axis to the observation point,

$$
\begin{gathered}
\left|\varphi_{s}(\phi)\right|^{2}=\frac{1}{k a} \sum_{m=0}^{\infty} \sum_{n=0}^{\infty} \varepsilon_{m} \varepsilon_{n} \sin \eta_{m} \sin \eta_{n} \cos \left(\eta_{m}-\eta_{n}\right) \\
\cos (m \phi) \cos (n \phi)
\end{gathered}
$$

$\phi$ is the angle between the incident and observation directions, $\mathrm{k}=2 \pi / \lambda, \lambda$ is the wavelength in the fluid surrounding the scatterer, $\varepsilon_{0}=1, \varepsilon_{\mathrm{m}}=2(\mathrm{~m}>0), \eta_{\mathrm{m}}$ is the phase angle for scattering from a cylinder given by [19]

$$
\tan \eta_{n}=\tan \delta_{n}(x) \frac{\tan \Phi_{n}+\tan \alpha_{n}(x)}{\tan \Phi_{n}+\tan \beta_{n}(x)},
$$

$\mathrm{x}=\mathrm{k} \alpha, \delta_{\mathrm{n}}(\mathrm{x})=\arctan \left[-\mathrm{J}_{\mathrm{n}}(\mathrm{x}) / \mathrm{N}_{\mathrm{n}}(\mathrm{x})\right], \alpha_{\mathrm{n}}(\mathrm{x})=\arctan [-$ $\left.\mathrm{xJ}_{\mathrm{n}}{ }^{\prime}(\mathrm{x}) / \mathrm{J}_{\mathrm{n}}(\mathrm{x})\right], \beta_{\mathrm{n}}(\mathrm{x})=\arctan \left[-\mathrm{xN}_{\mathrm{n}}{ }^{\prime}(\mathrm{x}) / \mathrm{N}_{\mathrm{n}}(\mathrm{x})\right], \tan \Phi_{\mathrm{n}}$ $=\left(-\rho / \rho_{1}\right) \tan \zeta_{n}\left(x_{1}, \sigma\right), \quad J_{m}$ and $N_{m}$ correspond to Bessel and Neumann functions, primes denote differentiation, $\rho$ is the density of the fluid surrounding the scatterer, $\rho_{1}$ is the density of the cylindrical scatterer, and $\sigma=$ Poisson's ratio $[19,20]$. A general form for the scattering phase angle, $\zeta_{\mathrm{n}}\left(\mathrm{x}_{1}, \sigma\right)$, may be found in Reference [19]. For inelastic scattering, $\tan \Phi_{\mathrm{n}}=0$ for all $\mathrm{n}$. For backscatter, $\phi=180^{\circ}$.

Scattered intensities for both inelastic and elastic scattering from a cylinder as functions of frequency are shown in Figure 2. For the elastic case, material properties for hydroxyapatite $\left(\mathrm{c}_{1}=\right.$ $6790 \mathrm{~m} / \mathrm{s}, \rho=3.22 \mathrm{~g} / \mathrm{cm}^{3}$, and $\left.\sigma=0.28\right)[21,22]$ scatterers in water were assumed. Deposits of calcium phosphate, similar to hydroxyapatite, are the major inorganic constituents of bone [23]. Anderson et al., in modeling microcalcifications in the breast, employed similar models for spherical scatterers composed of hydroxyapatite [22].

In the low frequency limit $(k \alpha<1)$, it may be shown that the intensity of the inelastically scattered wave is given by $\mathrm{I}_{s}=\pi \mathrm{k}^{3} \mathrm{a}^{4} \mathrm{I}(1-2 \cos \phi)^{2} / 8 \mathrm{r}$
[20] and is therefore proportional to the cube of the ultrasonic frequency at all angles.

This theory applies to a single cylindrical scatterer. It can also describe the frequency dependence of scattering from a superposition of scattered signals from many cylindrical sources provided that 1) echoes from different sources add incoherently (this will occur if the scatterers are positioned sufficiently randomly that the phases of their scattered waves may be taken to be uniformly distributed on the interval from 0 to $2 \pi[24,25])$ and 2 ) the effects of multiple scattering are negligible.

\section{METHODS}

Fourteen human calcanei were defatted using trichloro-ethylene. Defatting was presumed not to greatly affect measurements since attenuation $[4,26]$ and sound speed $[26,27]$ in defatted trabecular bone are similar to their counterparts with marrow left intact. The cortical lateral sides were sliced off. Samples were vacuum degassed underwater. Measurements were performed in distilled water at room temperature. The relative orientation between the ultrasound beam and the calcanei was the same as with commercial systems, in which sound propagates in the mediolateral (or lateromedial) direction.

A Panametrics (Waltham, MA) 5800 pulser/receiver and Panametrics circular, focussed, broadband transducers with center frequencies of $500 \mathrm{kHz}, 1 \mathrm{MHz}$, and $2.25 \mathrm{MHz}$ were used. Received ultrasound signals were digitized ( 8 bit, $10 \mathrm{MHz}$ ) using a LeCroy (Chestnut Ridge, NY) 9310C Dual $400 \mathrm{MHz}$ oscilloscope.

Backscatter coefficients were measured using a reference phantom method $[28,30]$. Attenuation measurements were required in order to compensate signals prior to backscatter coefficient estimation. Attenuation was measured using a standard through-transmission $\log$ spectral difference method [31]. The speed of sound in the calcaneus is sufficiently close to that of distilled water at room temperature that potential diffractionrelated errors in this substitution technique $[29,31]$ may be ignored. 


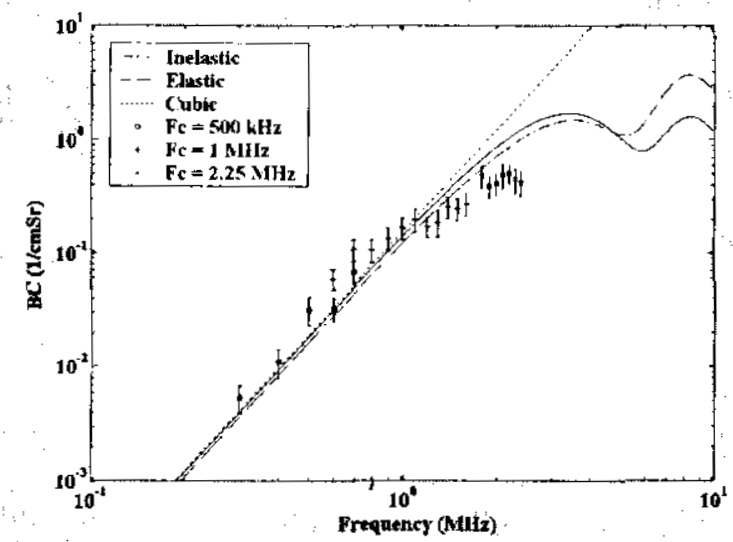

Figure 2. Backscatter coefficient vs. frequency in human calcaneus.

\section{RESULTS}

Figure 2 shows measurements of average backscatter coefficient for the 14 calcanei. Also shown are inelastic and elastic models assuming the material properties for hydroxyapatite and $\alpha=60$ $\mu \mathrm{m}$ [18]. Magnitudes of the theoretical curves were arbitrarily adjusted to fit the data. Good agreement in frequency dependence among both theoretical models and measurements may be seen. The low frequency data $(300-700 \mathrm{kHz})$ were least squares fit to power law functions, $\mathrm{Af}^{\mathrm{n}}$. The exponent, $\mathrm{n}$, was $3.31 \pm 0.22$ (mean \pm standard error), close to the expected cubic model.

\section{DISCUSSION}

A model describing the frequency dependence of backscatter from trabecular bone has been presented. Measurements in calcaneus in vitro agreed with theoretical predictions. For insonification in the mediolateral direction at low frequencies, including the typical diagnostic range, backscatter coefficient is proportional to frequency cubed. At higher frequencies, the frequency response flattens out.

\section{ACKNOWLEDGEMENTS}

Funding from the FDA Office of Women's Health and suggestions of Matthew Myers and William Sacks are greatly appreciated.

\section{REFERENCES}

[1] C.M. Langton, S.B. Palmer, and R.W. Porter. "The measurement of broadband ultrasonic attenuation in cancellous bone." Eng. in Med. 13, 89-91, 1984.

[2] P. Rossman, J. Zagzebski, C. Mesina, J. Sorenson, and R. Mazess, "Comparison of Speed of Sound and Ultrasound Attenuation in the Os Calcis to Bone Density of the Radius, Femur and Lumbar Spine," Clin. Phys. Physiol. Meas., 1989; 10:353-360.

[3] M.B. Tavakoli and J.A. Evans. "Dependence of the velocity and attenuation of ultrasound in bone on the mineral content." Phys. Med. Biol, 36, 1529-1537, 1991.

[4] C.M. Langton, C.F. Njeh, R. Hodgskinson, and J.D. Currey, Prediction of Mechanical Properties of the Human Calcaneus by Broadband Ultrasonic Attenuation, Bone, 18, 495-503, 1996.

[5] J.A. Zagzebski, P.J. Rossman, C. Mesina, R.B. Mazess, and E.L. Madsen. "Ultrasound transmission measurements through the os calcis." Calcif Tissue Int. 49, 107-111, 1991.

[6] C.F. Njeh, R. Hodgskinson, J.D. Currey, and C.M. Langton. "Orthogonal relationships between ultrasonic velocity and material properties of bovine cancellous bone." Med. Eng. Phys., 18, 373-381, 1996.

[7] S.R. Cummings, D.M. Black, M.C. Nevitt, W. Browner, J. Cauley, K. Ensrud, H.K. Genant, L. Palermo, J. Scott, and T.M. Vogt. "Bone density at various sites for prediction of hip fractures." Lancet, 341, 72-75, 1993.

[8] D. Hans, P. Dargent-Molina, A.M. Schott, J.L. Sebert, C. Cormier, P.O. Kotzki, P.D. Delmas, J.M. Pouilles, G. Breart, and P.J. Meunier, "Ultrasonographic heel measurements to predict hip fracture in elderly women: the EPIDOS prospective study," Lancet, 348, 511514, 1996.

[9] D.C. Bauer, C.C. Glüer, J.A. Cauley, T.M. Vogt, K.E. Ensrud, H.K. Genant, and D.M. Black. "Broadband ultrasound attenuation predicts fractures strongly and independently of densitometry in older women," Arch. Intern, Med. 157, 629-634 1997.

[10] A.M. Schott, S. Weill-Engerer, D. Hans, F. Duboeuf, P.D. Delmas, and P.J. Meunier, 
"Ultrasound discriminates patients with hip fracture equally well as dual energy X-ray absorptiometry and independently of bone mineral density." J. Bone Min. Res., 10, 243249, 1995.

[11] C.H. Turner, M. Peacock, L. Timmerman, J. M. Neal, and C.C. Johnston, Jr.,. "Calcaneal ultrasonic measurements discriminate hip fracture independently of bone mass," Osteo. Int'l, 5, 130-1351995.

[12] C.C. Glüer, S.R. Cummings, D.C. Bauer, K. Stone, A. Pressman, A. Mathur, and H.K. Genant, "Osteoporosis: Association of recent fractures with quantitative US findings", Radiol., 199, 725-732 1996.

[13] P. Thompson, J. Taylor, A. Fisher, and R. Oliver, "Quantitative heel ultrasound in 3180 women between 45 and 75 years of age: compliance, normal ranges and relationship to fracture history," Osteo. Int'1, 8, 211-214, 1998.

[14] V. Roberjot, P. Laugier, P. Droin, P. Giat, and G. Berger. Meaurement of integrated backscatter coefficient of trabecular bone. Proc. 1996 IEEE Ultrason. Symp. Vol. 2, 1123-1126, 1996.

[15] K.A. Wear and B.S. Garra. "Assessment of bone density using broadband ultrasonic backscatter," Proc. 22nd Symp. Ultrason. Imag. and Tissue Char., Washington, DC. 14, 1997.

[16] P. Giat, C. Chappard, C. Roux, P. Laugier, and G. Berger. Preliminary clinical assessment of the backscatter coefficient in osteoporosis, Proc. 22nd Symp. Ultrason. Imag. and Tissue Char., Washington, DC, 16, 1997.

[17] K.A. Wear and B.S. Garra. Assessment of bone density using ultrasonic backscatter. Ultrason. Med. \& Biol. 24, 689-695, 1998.

[18] K.D. Hausler, P.A. Rich, P.C. Smith, E.B. Barry. "Relationships between static histomorphometry and ultrasound in the human calcaneus." Calcif. Tissue. Int. 64:477-480, 1999.

[19] J.J. Faran, "Sound scattering by solid cylinders and spheres," J. Acoust. Soc. Am., 23, 405418, 1951.

[20] P.M. Morse and K.U. Ingard, Theoretical Acoustics. Princeton, NJ, Princeton University Press, 1986.

[21] D.E. Grenoble, J.L. Katz, K.L. Dunn, R.S. Gilmore, and $\mathrm{K}$. Lingamurty. The elastic properties of hard tissues and apatites, J. Biomed. Mater. Res., 6, 221-233, 1972.

[22] M.E. Anderson, M.S.C. Soo, and G.E. Trahey, Microcalcifications as elastic scatterers under ultrasound, IEEE Trans. Ultrason., Ferro., Freq. Cont. 45, 925-934.

[23] R.P. Heany, "Calcium," in Principles of Bone Biology, edited by J. P. Bilezikian, L. G. Raisz, and Gideon A. Rodan, (Academic Press, San Diego, 1996).

[24] M.O'Donnell and J.G. Miller, "Quantitative broadband ultrasonic backscatter: An approach to nondestructive evaluation in acoustically inhomogeneous materials," J. Appl. Phys. 52, 1056-1065, 1981.

[25] E.L. Madsen, M.F. Insana, and J.A. Zagzebski. "Method of data reduction for accurate determination of acoustic backscatter coefficients," J. Acoust. Soc. Am., 76, 913-923, 1984.

[26] J.M. Alves, J.T. Ryaby, J.J. Kaufman, P.P. Magee, and R.S. Siffert. Influence of marrow on ultrasounic velocity and attenuation in bovine trabecular bone. Calc. Tissue. Int., 58 , 362-367, 1996.

[27] C.F. Njeh and C.M. Langton. The effect of cortical endplates on ultrasound velocity through the calcaneus: an in vitro study. Brit. J. Radiol., 70, 504-510, 1997.

[28] J.A. Zagzebski, L.X. Yao, E.J. Boote, and Z.F. $\mathrm{Lu}$, "Quantitative Backscatter Imaging," in Ultrasonic Scattering in Biological Tissues, edited by K. K. Shung and G. A. Thieme, (CRC Press, Boca Raton, FL, 1993).

[29] P. Droin, G. Berger, and P. Laugier. Velocity dispersion of acoustic waves in cancellous bone. IEEE Trans. Ultrason. Ferro. Freq. Cont. 45, 581-592, 1998.

[30] K.A. Wear, B.S. Garra, and T.J. Hall, Measurements of ultrasonic backscatter coefficients in human liver and kidney in vivo, J. Acoust. Soc. Am., 98, 1852-1857 1995.

[31] W. $\mathrm{Xu}$ and J.J. Kaufman. Diffraction correction methods for insertion ultrasound attenuation estimation. IEEE Trans. Biomed. Eng. 40, 563-570, 1993. 